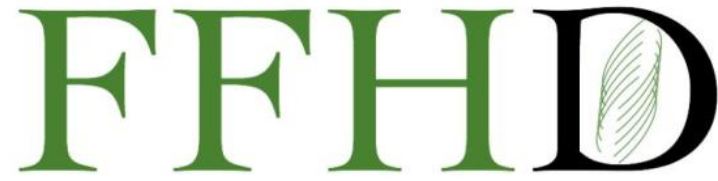

Functional Foods in Health and Disease

\title{
Adherence to the Mediterranean diet: An online questionnaire based-study in a Spanish population sample just before the Covid-19 lockdown
}

\author{
Ana Bagues ${ }^{1,2,3}$, Andrea Almagroํㅜㄹ ${ }^{1}$ Teresa Bermudez ${ }^{1}$, Yolanda López-Tofiño ${ }^{1,4}$, Antonio \\ Gonzalez $^{1,2,3}$, Raquel Abalo ${ }^{1,3,4,5^{*}}$
}

${ }^{1}$ Department of Basic Health Sciences, Universidad Rey Juan Carlos (URJC), Alcorcón, Spain; ${ }^{2}$ High Performance Research Group in Experimental Pharmacology (PHARMAKOM-URJC); ${ }^{3}$ Unidad Asociada I+D+i del Instituto de Química Médica (IQM), Consejo Superior de Investigaciones Científicas (CSIC), Madrid, Spain; ${ }^{4}$ High Performance Research Group in Physiopathology and Pharmacology of the Digestive System (NeuGut-URJC), Alcorcón, Spain; ${ }^{5}$ Grupo de Trabajo de Ciencias Básicas en Dolor y Analgesia de la Sociedad Española del Dolor, Madrid, Spain.

*Corresponding author: Raquel Abalo, Ph.D., Fac. Health Sciences, Universidad Rey Juan Carlos, Alcorcón, 28922, Madrid, Spain.

Submission Date: April 28 $8^{\text {th }}, 2021$; Acceptance Date: June $9^{\text {th }}, 2021$; Publication Date: June $29^{\text {th }}, 2021$

Please cite this article as: Bagues A., Almagro A., Bermudez T., López-Tofiño Y., Gonzalez A., Abalo R. Adherence to the Mediterranean diet: An online questionnaire based-study in a Spanish population sample just before the Covid19 lockdown. Functional Foods in Health and Disease. 2021; 11(6): 283-294. DOI: https://www.doi.org/10.31989/ffhd.v11i6.806

\section{ABSTRACT}

Background: The Mediterranean Diet (MD) has been associated with a reduced risk of developing several pathologies, such as cardiovascular diseases. Despite this, adherence to MD in the general population has decreased in the past years. Due to COVID-19 crisis, eating habits of the population are being affected, thus data assessing these habits just before lockdown are important to determine how they are modified. The Mediterranean Diet Quality Index (KIDMED) questionnaire was used to evaluate adherence to MD just before COVID-19 lockdown.

Methods: The KIDMED survey was launched through the Google platform for surveys, from 2/20/20 until 3/13/20. Additionally, questions about gender, weight and height for body mass index (BMI) calculation, academic degree, and nationality were included. Multivariate linear regression was performed for data analysis.

Results: A total of 861 completed surveys were collected. Some surveys were discarded because data was missing (18), the participants were not of Spanish nationality (18), or because they did not belong to the age groups 
included in the study (19). The remaining 804 surveys were divided into the following age groups: 15-24 ( $n=160)$, 25-34 ( $n=158), 35-54(n=363)$ and 55-69 $(n=123)$. In the 15-24-year-old group, 71.9\% had a BMI between 18-24.9, but only $28.1 \%$ reached an index $\geq 8$ in the KIDMED questionnaire. Adherence to MD improved as the age in the groups increased, but so did the BMI, especially in the oldest group. In all adult groups, approximately $50 \%$ had a university education. Overall, lower BMI was significantly related to females, younger age and a higher degree of studies. On the other hand, the higher adherence to MD was related to older age and a higher degree of education.

Conclusions: The improved adherence to MD was not associated with a reduced BMI. Maybe other factors, like sedentary life or hormonal changes, known to impact people while aging, have influenced our results. Possibly, adherence to MD might have played a protective role, at least partially, against an even higher BMI. More research is needed to fully determine the impact of adherence to MD in the Spanish population, also after COVID-19 lockdown.

\section{Do Spaniards adhere to the Mediterranean diet?}

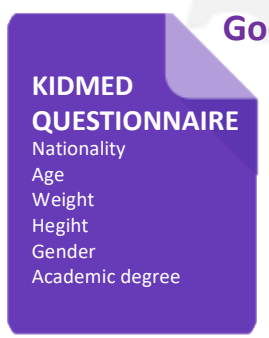

Google Forms

KIDMED

QUESTIONNAIRE

Nationality

Weight

Weight

Hegint

Academic degre

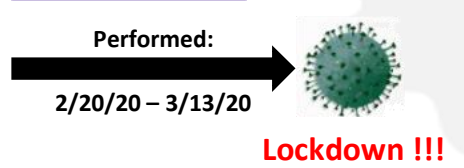

\section{Results}

$\checkmark \quad 804$ Surveys collected

DISTRIBUTION BY AGE AND SEX

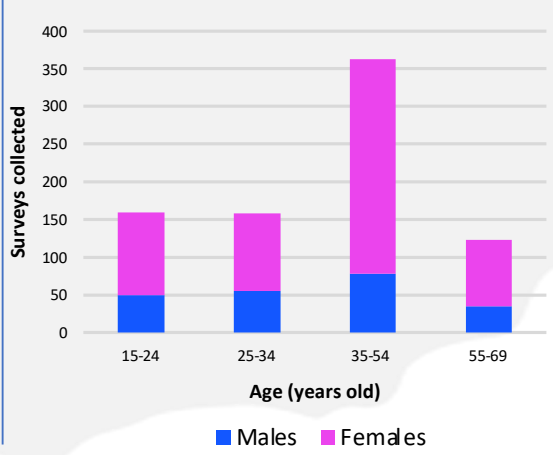

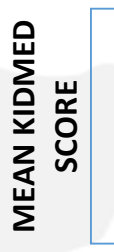

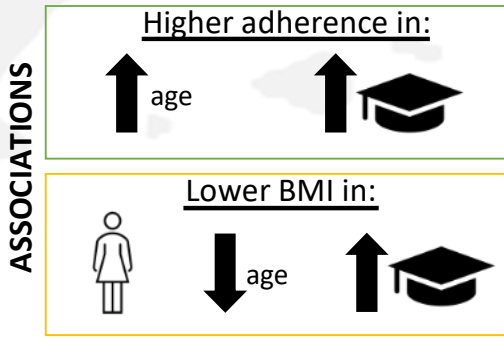

Keywords: Mediterranean diet, KIDMED, Body mass index, Spain.

CFFC 2021. This is an Open Access article distributed under the terms of the Creative Commons Attribution 4.0 License (http://creativecommons.org/licenses/by/4.0)

\section{INTRODUCTION}

The Mediterranean Diet (MD) is characterized by a high consumption of vegetables, legumes, fruits and nuts, unrefined cereals, olive oil, moderate intake of fish and low to moderate intake of dairy products, a low intake of meat and poultry and moderate intake of alcohol, mainly in the form of wine. Additionally, it involves the consumption of local and seasonal products and is enriched by its associated social habits such as considering eating a social event, frugality and sobriety. It was recognized by the UNESCO in 2010 as an Intangible Heritage of Humanity [1].

The MD has been shown to be a protective factor in the development of different diseases such as cardiovascular disease, type 2 diabetes mellitus or different tumors [2]. On the other hand, a high adherence to MD is associated with a high life 
expectancy, lower morbidity and mortality [3]. Despite its benefits, in the last years, there has been a decline in the adherence of the population to this diet due to the social and cultural changes that occurred and also due to globalization [4-7]. Thus, people have shifted towards a more Western type of diet, characterized by an ingestion of high content of proteins (derived from fatty domesticated and processed meats), saturated fats, refined grains, sugar, alcohol, salt, and corn-derived fructose syrup, with an associated reduced consumption of fruits and vegetables [8]. This phenomenon is related to the increase in childhood obesity in different regions of the Mediterranean area [9]. Importantly, a study that analyzed adherence to MD in 8 European countries found the lowest adherence to this diet in Spanish school-aged girls [10].

Additionally, the adherence to MD is different among different age groups. Previous studies have demonstrated that this adherence is higher in older age groups in several countries in the Mediterranean Basin [6,11-14].

Another situation that has recently modified the adherence to MD has been the crisis associated to COVID-19, with contradicting results. Thus, whilst in some countries, adherence has worsened [15-16], in Spain there has been an increase in the adherence to MD [17-18]. However, these previous studies collected and analyzed the data on eating habits during the first weeks-months of the pandemic, and not just before this situation started. Thus, when answering questions regarding pre-pandemic eating habits during the lockdown, an important recall bias may have influenced the results. Data on the eating habits obtained from questionnaires answered just before lockdown may offer more accurate information about these habits, which can be very useful as a baseline for further studies.

The Mediterranean Diet Quality Index for Children and Adolescents (KIDMED) questionnaire was initially validated in Spain by Serra-Majem et al., in 2004 to study the possible adherence of the population to the MD [19]. Nowadays, this is one of the most internationally used measures [20]. Posteriorly, its use was validated in young adults up to 24 years old [21] and has also proved to be an effective tool in studying the adherence to the MD in adults [22]. Up to date, the adherence to the MD has been studied separately in school children, adolescents, college university or adults, but very few studies have compared the adherence to the MD across different age groups.

Thus, our aim was to compare the adherence to the MD in 4 different age groups of the Spanish population. Importantly, the study was performed, and data collected during the three weeks prior to the COVID-19 "State of Alarm" and lockdown in Spain, when Spaniards did not know that they would be suffering a rigid confinement soon after.

\section{METHODS}

Participants' recruitment: The KIDMED survey was created using the Google Forms tool. Diffusion of the questionnaire was performed using instant messaging apps e.g., WhatsApp, social media such as Facebook and Twitter, social networking sites such as LinkedIn and ResearchGate and emails through snowball sampling, in an attempt to cover the whole Spanish territory and to reach the greatest number of 
persons through mobile phones, tablets and computers. The survey was open from 2/20/20 until 3/13/20 (just before the COVID-19 lockdown).

A cross-sectional study was carried out among Spanish adults who were encouraged to participate in the present study without any exclusion criteria. The study was conducted in agreement with the Declaration of Helsinki, and all data were collected anonymously and recorded according to the Spanish Organic Law of Personal Data Protection (LOPD) 15/1999. Since the questionnaire was anonymous and no sensible personal data were collected, no informed written consent was requested. However, participants were informed about the objective of the research. Participation in the online questionnaire was entirely voluntary. Whether or not the completed questionnaire was submitted was according to the final decision of the respondent to participate. Only completed questionnaires were included in the analysis.

KIDMED survey and questionnaire: The KIDMED test was composed of 16 questions concerning daily eating habits, with a simple "yes" or "no" answer. Questions denoting a negative connotation with respect to the MD are assigned a value of -1 , and those with a positive aspect a value of +1 (see Table 1). The sums of the values from the administered test are classified into three levels: (1) > 8, optimal Mediterranean diet; (2) 4-7, improvement needed to adjust intake to Mediterranean patterns; (3) $<3$, very low diet quality [19].

Table 1. Mediterranean diet Quality Index for Children and Adolescents (KIDMED) test to assess Mediterranean diet adherence [19].

\begin{tabular}{|l|l|}
\hline Questions & Scoring \\
\hline Takes a fruit or fruit juice every day & +1 \\
\hline Has a second fruit every day & +1 \\
\hline Has fresh or cooked vegetables regularly once a day & +1 \\
\hline Has fresh or cooked vegetables more than once a day & +1 \\
\hline Consumes fish regularly (at least 2-3 times per week) & +1 \\
\hline Goes more than once a week to a fast-food (hamburger) restaurant & -1 \\
\hline Likes pulses and eats them more than once a week & +1 \\
\hline Consumes pasta or rice almost every day (5 or more times per week) & +1 \\
\hline Has cereals or grains (bread, etc.) for breakfast & +1 \\
\hline Consumes nuts regularly (at least 2-3 times per week) & +1 \\
\hline Uses olive oil at home & +1 \\
\hline Skips breakfast & -1 \\
\hline Has a dairy product for breakfast (yoghurt, milk, etc.) & +1 \\
\hline Has commercially baked goods or pastries for breakfast & -1 \\
\hline Takes two yoghurts and/or some cheese (40 g) daily & +1 \\
\hline Takes sweets and candy several times every day & -1 \\
\hline
\end{tabular}

In addition to the KIDMED test, questions on gender, age, nationality, level of studies and anthropometric data (weight in kilograms and height in $\mathrm{cm}$ ) were also asked.

Age, body mass index and educational degree: The results of the questionnaire were downloaded to an excel spreadsheet to classify them in the following age groups: 15-24, 25-34, 35-54 and 55-69 years old.
This was done for both male and female respondents.

These age intervals were chosen according to the different stages of life, most typical in Spain, as follows: 
- Age 15-24: at this stage, most individuals are normally still studying and live at their parents' home

- $\quad$ Age 25-34: at this stage, important changes frequently occur. It is when individuals finish college education, start working and have more economical independence, and start forming a family

- $\quad$ Age 35-54: at this stage, adults become more stable

- Age 55-69: older adults in which physiological changes occur, although normally still relatively active and with reasonably good health.

The body mass index (BMI) of each participant was calculated as a proxy to nutritional status [1]. BMI were calculated with the following formula: $\mathrm{BMI}=$ weight $(\mathrm{kg}) /(\text { height }(\mathrm{m}))^{2}$ and depending on the result categorized in the following groups: (1) below 18.5 underweight; (2) 18.5-24.9 normal or healthy weight; (3) 25-29.9 overweight; (4) 30 or above obese.

The level of studies was classified as primary (primary or elementary school), secondary (high school) or advanced education (university).

Statistical analysis: The data were analyzed with Graphpad Prism software v.9 and are presented as the percentage of population studied or as the means \pm S.D. From previous studies, it is known that the standard deviation of the average KIDMED index is around 2, with an effect size of 1 , and thus, a standardized size of 0.5 . Assuming a confidence level of $95 \%$ and a desired potency of $90 \%$, the minimum number of participants would be 86 [17]. Differences in the $\mathrm{BMI}$ and adherence to the Mediterranean diet between gender and age groups were analyzed by a Two-Way ANOVA followed by Sidak's multiple comparison test. To analyze the relation between $\mathrm{BMI}$ and adherence to gender, age and educational degree, multivariate linear regression was performed, where BMI and the KIDMED results were established as dependent variables.

RESULTS

Sample description: A total of 859 surveys were collected. 18 surveys were discarded because some data were missing, 18 because the participants were not of Spanish nationality and 19 because they did not belong to the age groups included in the study. Thus, the remaining 804 surveys were divided into the following age groups: 15-24 ( $n=160$, males=49; females=111), $\quad 25-34 \quad(n=158, \quad$ males $=55$; females=103), 35-54 ( $n=363$, males=78; females=285) and 55-69 ( $n=123$, males=34; females=89).

The level of education of the different groups can be seen in table 2, the distribution of the BMI in table 3 , and the adherence to the MD in table 4. 
Table 2. Educational degree.

\begin{tabular}{|c|c|c|c|c|}
\hline $\begin{array}{l}\text { Age } \\
\text { (years) }\end{array}$ & Gender & $\begin{array}{c}\text { Primary education } \\
\text { (\%) }\end{array}$ & $\begin{array}{c}\text { Secondary education } \\
\text { (\%) }\end{array}$ & $\begin{array}{c}\text { Advanced education } \\
(\%)\end{array}$ \\
\hline \multirow[t]{3}{*}{$15-24$} & Males & 12.2 & 55.1 & 32.7 \\
\hline & Females & 4.5 & 36.9 & 58.6 \\
\hline & TOTAL & 6.9 & 42.5 & 50.6 \\
\hline \multirow[t]{3}{*}{$25-34$} & Males & 20.0 & 32.7 & 47.3 \\
\hline & Females & 16.5 & 23.3 & 60.2 \\
\hline & TOTAL & 17.7 & 26.6 & 55.7 \\
\hline \multirow[t]{3}{*}{$35-54$} & Males & 17.9 & 28.2 & 53.8 \\
\hline & Females & 17.2 & 30.9 & 51.9 \\
\hline & TOTAL & 17.4 & 30.3 & 52.3 \\
\hline \multirow[t]{3}{*}{$55-69$} & Males & 17.6 & 29.4 & 52.9 \\
\hline & Females & 19.1 & 31.5 & 49.4 \\
\hline & TOTAL & 18.7 & 30.9 & 50.4 \\
\hline
\end{tabular}

Values are expressed as percentage for each group according to age and sex within each educational level category.

Table 3. Body mass index.

\begin{tabular}{|c|c|c|c|c|c|}
\hline $\begin{array}{l}\text { Age } \\
\text { (years) }\end{array}$ & Gender & $\begin{array}{c}\mathrm{BMI}<18.5 \\
(\%)\end{array}$ & BMI 18.5-24.9 (\%) & $\begin{array}{c}\text { BMI 25-29.9 } \\
\text { (\%) }\end{array}$ & $\mathrm{BMI}>\mathbf{3 0}(\%)$ \\
\hline \multirow[t]{3}{*}{$15-24$} & Males & 4.1 & 75.5 & 16.3 & 4.1 \\
\hline & Females & 15.3 & 70.3 & 13.5 & 0.9 \\
\hline & TOTAL & 11.9 & 71.9 & 14.4 & 1.9 \\
\hline \multirow[t]{3}{*}{$25-34$} & Males & 1.8 & 58.2 & 29.1 & 10.9 \\
\hline & Females & 4.9 & 72.8 & 17.5 & 4.9 \\
\hline & TOTAL & 3.8 & 67.7 & 21.5 & 7.0 \\
\hline \multirow[t]{3}{*}{$35-54$} & Males & 0.0 & 39.7 & 39.7 & 20.5 \\
\hline & Females & 2.5 & 59.3 & 25.6 & 12.6 \\
\hline & TOTAL & 1.9 & 55.1 & 28.7 & 14.3 \\
\hline \multirow[t]{3}{*}{$55-69$} & Males & 2.9 & 26.5 & 44.1 & 26.5 \\
\hline & Females & 2.2 & 43.8 & 39.3 & 14.6 \\
\hline & TOTAL & 2.4 & 39.0 & 40.7 & 17.9 \\
\hline
\end{tabular}

Values are expressed as percentage for each group according to age and sex within each BMI category. BMI, body mass index. 
Table 4. Adherence to the Mediterranean diet according to the KIDMED index.

\begin{tabular}{|l|l|l|l|l|}
\hline Age (years) & Gender & $\begin{array}{l}\mathbf{3} \\
\mathbf{( \% )}\end{array}$ & $\begin{array}{l}\mathbf{4}-\mathbf{7} \\
\mathbf{( \% )}\end{array}$ & $\begin{array}{l}\mathbf{2 8} \\
\mathbf{( \% )}\end{array}$ \\
\hline $\mathbf{1 5 - 2 4}$ & Males & 12.2 & 55.1 & 32.7 \\
\hline & Females & 14.4 & 59.5 & 26.1 \\
\hline \multirow{2}{*}{$25-34$} & TOTAL & 13.8 & 58.1 & 28.1 \\
\hline & Males & 9.1 & 41.8 & 49.1 \\
\hline \multirow{2}{*}{$35-54$} & Females & 3.9 & 46.6 & 49.5 \\
\hline & TOTAL & 5.7 & 44.9 & 49.4 \\
\hline \multirow{2}{*}{$55-69$} & Males & 9.0 & 48.7 & 42.3 \\
\hline & Females & 4.9 & 39.3 & 55.8 \\
\hline & TOTAL & 5.8 & 41.3 & 52.9 \\
\hline & Males & 8.8 & 41.2 & 50.0 \\
\hline & Females & 4.5 & 27.0 & 68.5 \\
\hline & TOTAL & 5.7 & 30.9 & 63.4 \\
\hline
\end{tabular}

Values are expressed as percentage for each group according to age and sex within each KIDMED category. KIDMED, Mediterranean Diet Quality Index for Children and Adolescents.

Body mass index: Overall, the BMI tended to increase with age, the values being significantly higher at the 35-54 and 55-69 age groups when compared to the youngest one. Interestingly, females presented lower BMI than males in the middle age groups (25-34 and 35-54) (Figure 1).

\section{Body mass index}

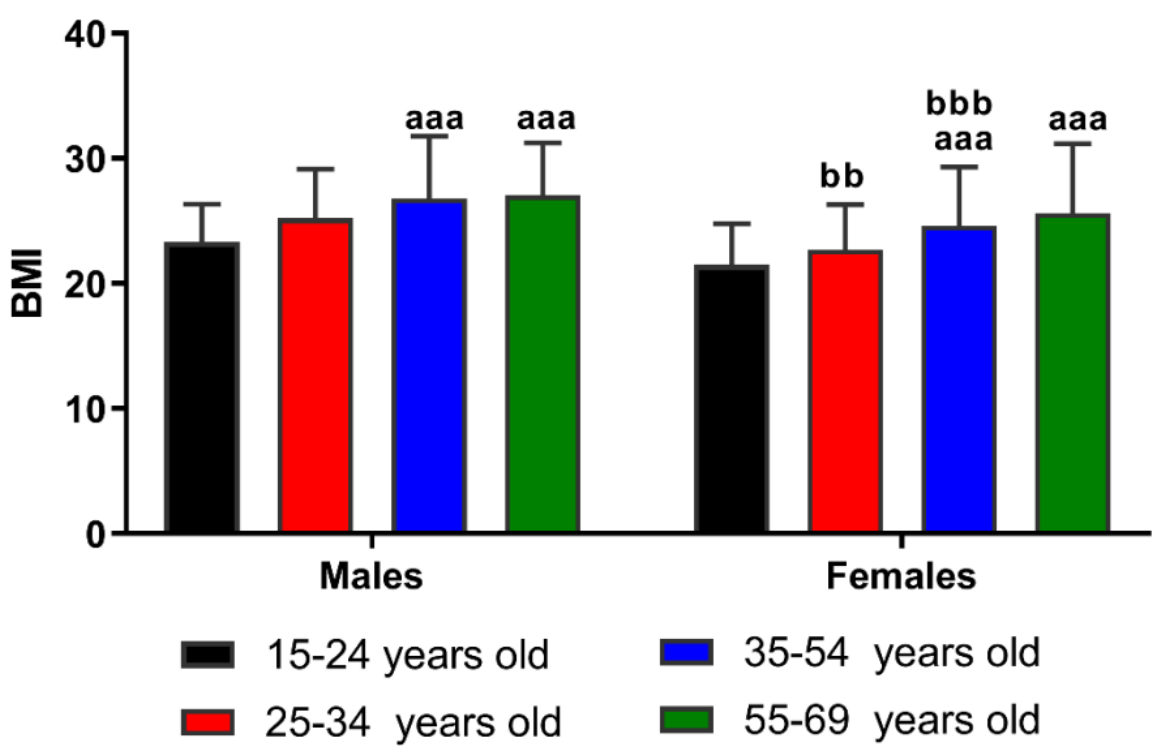

Figure 1. Body mass index of males and females in the following age groups: 15-24, 25-34, 35-54 and 55-69 years old. Data is presented as the means \pm SD. aaa $p<0.001$ vs the $15-24$ age group of the same gender; $b b p<0.01 ; b b b$ $p<0.001$ vs males in the same agegroup. Two-way ANOVA followed by Sidak's multiple comparison test. 
Adherence to Mediterranean diet: As seen in figure

2, adherence to Mediterranean diet was not significantly modified through the different age groups in males, whilst in females there was an increase in the adherence as the age groups got older. On the other hand, females in the oldest age group had a higher adherence to the Mediterranean diet than males in that same age group.

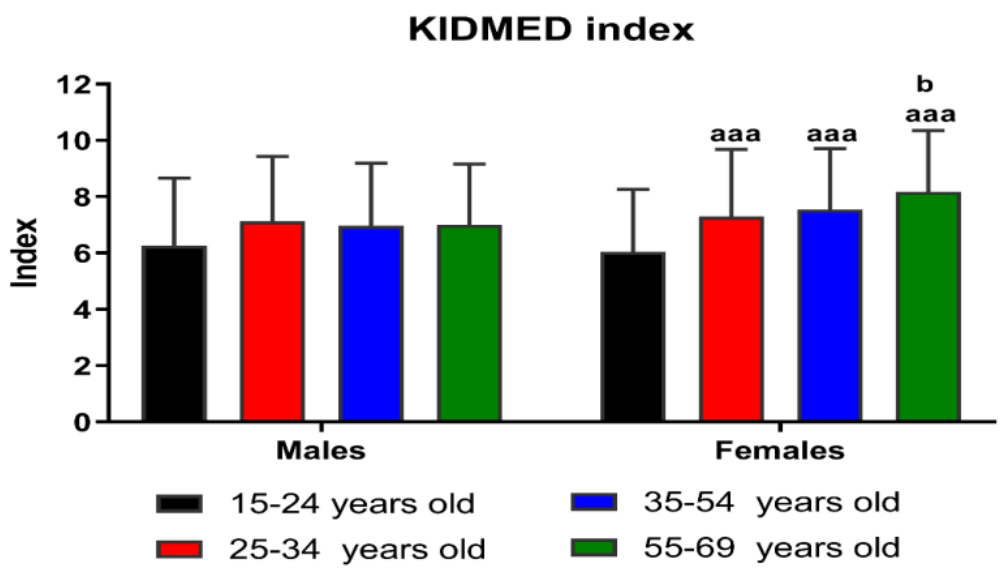

Figure 2. Adherence to the Mediterranean diet (KIDMED index) in the following age groups: 15-24, 25-34, 35-54 and 55-69 years old. Data is presented as the means \pm SD. aaa $p<0.001$ vs the female $15-24$ age group; $b$ p $<0.05$ vs males in the same age group. Two-way ANOVA, followed by Sidak's multiple comparison test.

Factors associated to BMI and MD adherence: When studying the relation of the KIDMED index and BMI with gender, age and level of studies, multiple linear regression analysis showed that lower BMI correlated with females $(p<0.001)$, higher level of studies $(p<0.001)$ and younger age $(p<0.001)$. On the other hand, a higher KIDMED index was associated to older age $(p<0.001)$ and higher educational degree $(p<0.001)$.

\section{DISCUSSION}

In the present study, we evaluated the adherence to the $M D$ in a sample of the Spanish population from 14-69 years old, just before the COVID-19 lockdown and "State of alarm" was stablished on March $14^{\text {th }}$, 2020 in our country. Importantly, at the time of questionnaire filling, the participants were not aware of the upcoming confinement situation.

We have found that the adherence to the MD increased with age, although more significantly in females. On the other hand, the mean KIDMED score was not modified throughout the different age groups in males, whilst there was an increase in females as the groups increased in age. BMI was also increased in the two oldest groups in both males and females, and females in the middle-aged groups (2554 years old) had lower BMI than males. When analyzing which factors were associated with a higher adherence to MD, we found that age and educational degree had a positive correlation. Lower BMI positively correlated with females and educational degree, but inversely to age. We did not find that BMI and adherence to MD were correlated in our sample.

In the present study, the youngest group presented the lowest adherence to the MD, with $13.8 \%$ (12.2 males and 14.4 females) of the participants in this age having a very low adherence, $58 \%$ (55.1 males and 59.1 females) scoring from 3-7 and only $28 \%$ (32.7 males and 26.1 females) displaying a very high adherence to MD. Curiously, our results are strikingly similar to those obtained in a population of adolescents in the city of Mataró (Catalonia, Spain) [23]. The authors found that, in high school male students, $12.6 \%$ had a very low 
adherence, $54.1 \%$ had a moderate adherence, and $33.3 \%$ a high adherence. In the case of females, $8.7 \%$ graded with a low adherence, $64.3 \%$ with a moderate adherence, and $27 \%$ with a high adherence. On the other hand, previous studies have shown that there are differences in the adherence to the MD depending on the Spanish autonomous community [19]. Our results were obtained from all over Spain, although, unfortunately, at this stage it was not possible to stratify the data according to the place of residence of the participants, thus possible differences due to region could have been diluted. Additionally, although very few studies have used the KIDMED index in older populations, in the study performed by Iturriagui et al., 2019 [22], also in Spain, a population of 35-55-year-old women with a mean age of $43.67 \pm 5.26 \mathrm{had}$ a mean index of $7.52 \pm 2.99$. Our scores for females in these age ranges were: 25-39 year old 7.54 and that between 40-69 8.17, thus very similar to the one found in the population of Iturriagui et al [22], particularly for the youngest women; the slightly higher MD values found in the oldest age group might be due to the inclusion of people until 69 , because MD adherence increases with age, as discussed below.

Overall, females had lower BMI than males. In all age groups there was a higher percentage of females with a BMI below 18.5 and a higher percentage of males with BMI compatible with the presence of overweight and obesity. One of the limitations of this study is that we did not ask about the level of physical activity and it has been demonstrated that, in general, males perform more physical activity than females [24], which increases $\mathrm{BMI}$, thus another possibility is that males also had higher BMI due to more volume of skeletal muscle mass.

Although the mean KIDMED index was not different amongst males and females, there was a higher percentage of females which had a higher adherence to $\mathrm{MD}$, when the whole sample was considered. As the age in the different groups was increased, so did the adherence in the MD in females, whilst in males no differences were observed. At the oldest age group, females had a significantly higher adherence than males to MD. Because we have not found previous studies analyzing differences across ages, we cannot know the reason for this, but several factors, or a combination of them could explain this difference such as the fact that people eat less and make different food choices as they get older, with a tendency to consume less energy-dense sweets and fast foods, and consume more grains, vegetables and fruits [25]. Although it is relevant to mention that we have only included those participants whose age was up to 69 , from this age, changes like reduced physical and social activity, reduced care for keeping a specific physical appearance, as well as the increasing occurrence of morbidities and appetite loss, might modify adherence to the MD, which warrants further investigation. Also, gender influences food preferences and women were demonstrated to be more inclined to a Mediterranean dietary profile [2627]. Additionally, a previous study has found that adult females with a mean age of 36 years old presented higher adherence index to the MD than males [28], and this occurred also during the COVID19 lockdown [17-18]. Thus, regardless of the situation, females tend to adhere more to MD.

Although older age correlated with higher adherence to $\mathrm{MD}$, it also correlated to a higher BMI, as previously reported [29-30]. Maybe other factors, such as sedentary life or hormonal changes, known to impact people while aging [31-32], have influenced our results. At the same time, adherence to MD might have played a protective role, at least partially, against an even higher BMI [33].

On the other hand, we observed that lower BMI correlated with females, and that females in the oldest age group had a greater adherence to MD than males, which agrees with previous studies [26-27], and with a higher educational level. The relationship 
between degree of education and BMI has been extensively studied and many reports have found this association [34-35]. This could be because the higher the education degree, the higher the nutritional knowledge and the individual awareness concerning food related issues, which, together with a normally higher income, favors individuals to be more prone to follow balanced dietary patterns [34,36]. Additionally, previous studies highlighted that high education is also positively associated with environmental attitudes and increased proenvironmental behaviors [37], which favors healthier, more sustainable food choices, amongst other beneficial effects for both the individual and the environment.

In addition to the issues discussed above (i.e., the lack of information on the level of physical activity), some limitations to this study must be acknowledged, such as the predominance of females in the sample and the very low percentage of participants with a low educational degree which could be due to the method that was used to obtain the results of the KIDMED questionnaire (nonrandom snow-ball sampling method). However, Ekman et al. [38] affirmed that the bias associated with collecting information using online questionnaires was not greater than that caused by paper questionnaires. Additionally, since the questionnaire was self-administered and online, participants did not have the opportunity to ask about any doubts that could be presented. However, the KIDMED is a validated and widely used instrument for rapid estimation of adherence to the Mediterranean diet which does not seem to raise big doubts [19]. Finally, the World Health Organization (WHO) had declared COVID-19 as a pandemic on the 11th of March, and this might have influenced the eating habits of some of the responders, though we believe this unlikely affected our results because only 2 surveys were collected on the 11th of March or after.
Probably the most important limitation of our study has to do with the declaration of the pandemic on that date. Indeed, not all of the groups evaluated reached the minimum number of participants required according to the power calculation analysis, unfortunately. The Survey was initially planned to last for a few more weeks, so that we expected to reach that minimum number of participants per group (i.e., 86). However, due to the occurrence of the pandemic and the COVID-19 lockdown, we decided to limit the study to the data collected before the 13th of March, so that the results would correspond only to the "normal" eating habits just prior to confinement. Despite this limitation, imposed by the unusual pandemic situation, we consider that our report provides important information for further studies, particularly regarding women.

\section{CONCLUSION}

Overall, adherence to $\mathrm{MD}$ is medium in the young population and tends to increase with age, especially in the female population. Lower BMI are associated to younger age, higher educational degree and females, whilst adherence to $M D$ is only related to older age and higher educational degree.

The information on the adherence to MD collected here, just before COVID-19 lockdown, offers relevant baseline data for new studies addressing issues such as the impact of the economic crisis derived from the pandemic situation on the eating habits of the Spanish population in the near future.

Abbreviations: BMI: body mass index, KIDMED: Mediterranean Diet Quality Index for Children and Adolescents, LOPD: Spanish Organic Law of Personal Data Protection 15/1999, MD: Mediterranean diet, URJC: Universidad Rey Juan Carlos, WHO: World Health Organization.

Competing Interests: Authors declare no conflict of interest. 
Author Contributions: $A B, A G$ and RA designed the study. AA and TB collected the data. AB, YLT and AG analyzed the data. $A B$ wrote the original draft. RA critically reviewed and edited the manuscript. All authors approved the final manuscript.

\section{REFERENCES}

1. Bonaccorsi G, Furlan F, Scocuzza M, Lorini C. Adherence to mediterranean diet among students from primary and middle school in the Province of Taranto, 2016-2018. Int J Environ Res Public Health 2020, 17: 110. https://doi.org/10.3390/ijerph17155437.

2. Li Y, Schoufour J, Wang DD, Dhana K, Pan A, Liu X, et al. Healthy lifestyle and life expectancy free of cancer, cardiovascular disease, and type 2 diabetes: Prospective cohort study. BMJ. 2020, 368 https://doi.org/10.1136/bmj.16669.

3. Grassi T, Bagordo F, Panico A, De Giorgi M, Idolo A, Serio $\mathrm{F}$, et al. Adherence to Mediterranean diet of children living in small Southern Italian villages. Int J Food Sci Nutr 2020, 71: 490-499. https://doi.org/10.1080/09637486.2019.1679725.

4. Bonaccio M, Di Castelnuovo A, Bonanni A, Costanzo S, De Lucia F, Persichillo $M$, et al. Decline of the Mediterranean diet at a time of economic crisis. Results from the Moli-sani study. Nutr Metab Cardiovasc Dis 2014, 24: 853-860. https://doi.org/10.1016/j.numecd.2014.02.014

5. Giuseppe R di, Bonanni A, Olivieri M, Castelnuovo A Di, Donati MB, Gaetano $G$ de, et al. Adherence to Mediterranean diet and anthropometric and metabolic parameters in an observational study in the "Alto Molise" region: The MOLI-SAL project. Nutr Metab Cardiovasc Dis 2008, 18: 415-421. https://doi.org/10.1016/j.numecd.2007.05.010.

6. León-Muñoz LM, Guallar-Castillón P, Graciani A, LópezGarcía E, Mesas AE, Aguilera MT, et al. Adherence to the mediterranean diet pattern has declined in Spanish adults. J Nutr 2012, 142: 1843-1850. https://doi.org/10.3945/jn.112.164616.

7. Sofi F, Vecchio S, Giuliani G, Marcucci R, Gori AM, Fedi $S$, et al. Dietary habits, lifestyle and cardiovascular risk factors in a clinically healthy Italian population: The "Florence" diet is not Mediterranean. Eur J Clin Nutr 2005, 59: 584-591. https://doi.org/10.1038/sj.ejcn.1602112.

8. Statovci D, Aguilera M, MacSharry J, Melgar S. The I mpact of western diet and nutrients on the microbiota and immune response at mucosal interfaces. Front Immuno 2017, 28(8): 838. https://doi.org/10.3389/fimmu.2017.00838.

9. Bonaccio $\mathrm{M}$, lacoviello $\mathrm{L}$, De Gaetano $\mathrm{G}$. The
Acknowledgements and Funding: The authors have not received any funding to support this research. We thank Comunidad Autónoma de Madrid (PEJD-2017PRE/BMD-3924) and URJC (PREDOC20-054) for the predoctoral contract of Y. López-Tofiño.

Mediterranean diet: The reasons for a success. Thromb Res 2012, 129(3):401-404 https://doi.org/10.1016/j.thromres.2011.10.018.

10. Tognon G, Moreno LA, Mouratidou T, Veidebaum T, Molnár D, Russo $\mathrm{P}$, et al. Adherence to $\mathrm{a}$ Mediterranean-like dietary pattern in children from eight European countries. The IDEFICS study. Int J Obes 2014, 38: S108-S114..https://doi.org/10.1038/ijo.2014.141.

11. Monteagudo C, Mariscal-Arcas M, Rivas A, LorenzoTovar ML, Tur JA, Olea-Serrano F. Proposal of a mediterranean diet serving score. PLoS One 2015, 10: e0128594 https://doi.org/10.1371/journal.pone.0128594.

12. Grosso G, Marventano S, Giorgianni G, Raciti T, Galvano F, Mistretta A. Mediterranean diet adherence rates in Sicily, southern Italy. Public Health Nutr 2014, 17: 20012009. https://doi.org/10.1017/S1368980013002188.

13. Kyriacou A, Evans JMM, Economides N, Kyriacou A. Adherence to the Mediterranean diet by the Greek and Cypriot population: A systematic review. Eur J Public Health 2015, 25: 1012-1018. https://doi.org/10.1093/eurpub/ckv124.

14. Benhammou S, Heras-González L, Ibáñez-Peinado D, Barceló C, Hamdan M, Rivas A, et al. Comparison of Mediterranean diet compliance between European and non-European populations in the Mediterranean basin. Appetite 2016, 107: 521-526. https://doi.org/10.1016/j.appet.2016.08.117.

15. Galali Y. The impact of COVID-19 confinement on the eating habits and lifestyle changes: A cross sectional study. Food Sci Nutr 2021, 16;9(4):2105-2113. doi:10.1002/fsn3.2179.

16. Giacalone D, Frøst MB, Rodríguez-Pérez C. Reported Changes in Dietary Habits During the COVID-19 Lockdown in the Danish Population: The Danish COVIDiet Study. Front Nutr 2020, 8(7): 592112. https://doi.org/10.3389/fnut.2020.592112.

17. Tárraga Lopez PJ, Panisello Royo JM, Carbayo Herencia JA, Carro A, Rosich N, Panisello M, et al. Changes in adherence to the mediterranean diet observed in a spanish population during confinement for the sars-cov2 pandemic. Nutr Hosp 2021, 38: 109-120. https://doi.org/10.20960/nh.03275.

18. Rodríguez-Pérez C, Molina-Montes $E$, Verardo $V$, Artacho R, García-Villanova B, Guerra-Hernández EJ, et al. Changes in dietary behaviours during the COVID-19 
outbreak confinement in the Spanish COVIDiet study. Nutrients 2020, 12: 1-19. https://doi.org/ 10.3390/nu12061730.

19. Serra-Majem L, Ribas L, Ngo J, Ortega RM, García A Pérez-Rodrigo $C$, et al. Food, youth and the Mediterranean diet in Spain. Development of KIDMED, Mediterranean Diet Quality Index in children and adolescents. Public Health Nutr 2004, 7: 931-935. https://doi.org/ 10.1079/phn2004556.

20. Atencio-Osorio MA, Carrillo-Arango HA, CorreaRodríguez M, Ochoa-Muñoz AF, Ramírez-Vélez R. Adherence to the mediterranean diet in college students: Evaluation of psychometric properties of the kidmed questionnaire. Nutrients. 2020, 12: 1-10. doi:10.3390/nu12123897.

21. Štefan L, Prosoli R, Juranko D, Čule M, Milinović I, Novak $D$, et al. The reliability of the mediterranean diet quality index (KIDMED) questionnaire Nutrients. 2017 23;9(4):419 https://doi.org/10.3390/nu9040419.

22. Iturriaga T, Barcelo O, Diez-Vega I, Cordero J, Pulgar S, Fernandez-Luna A, et al. Effects of a short workplace exercise program on body composition in women: $A$ randomized controlled trial. Health Care Women Int. 2020, 41: 133-146. https://doi.org/10.1080/07399332.2019.1679813.

23. Arcila-Agudelo AM, Ferrer-Svoboda C, TorresFernàndez $\mathrm{T}$, Farran-Codina $\mathrm{A}$. Determinants of adherence to healthy eating patterns in a population of children and adolescents: Evidence on the mediterranean diet in the city of Mataró (Catalonia, Spain). Nutrients. 2019, 11(4):854

https://doi.org/10.3390/nu11040854.

24. The Lancet Public Health. Time to tackle the physical activity gender gap. The Lancet Public Health. Elsevier Ltd; 2019, 4(8): e360. doi:10.1016/S24682667(19)30135-5.

25. Drewnowski A, Shultz JM. Impact of aging on eating behaviors, food choices, nutrition, and health status. In: Journal of Nutrition, Health and Aging [Internet]. 2001 [cited 15 Apr 2021] pp. 75-79. Available: https://pubmed.ncbi.nlm.nih.gov/11426286/.

26. Westenhoefer J. Age and gender dependent profile of food choice. Forum Nutr 2005, 57: 44-51. https://doi.org/10.1159/000083753.

27. Wardle J, Haase AM, Steptoe A, Nillapun M, Jonwutiwes K, Bellisle F. Gender Differences in Food Choice: The Contribution of Health Beliefs and Dieting. Ann Behav Med 2004, 27: 107-116. https://doi.org/10.1207/s15324796abm2702_5.

28. Barrea L, Muscogiuri G, Laudisio D, Pugliese G, de Alteriis $\mathrm{G}$, Colao $\mathrm{A}$, et al. Influence of the mediterranean diet on 25-hydroxyvitamin $D$ levels in adults. Nutrients. 2020, 16;12(5): 1439 https://doi.org/10.3390/nu12051439.
29. Ogden $C L$, Carroll MD, Curtin LR, McDowell MA, Tabak CJ, Flegal KM. Prevalence of overweight and obesity in the United States, 1999-2004. J Am Med Assoc 2006, 295: 1549-1555. https://doi.org/10.1001/jama.295.13.1549.

30. Sakamoto M. The situation of the epidemiology and management of obesity in Japan. Int J Vitam Nutr Res 2006, 76(4):253-256. https://doi.org/10.1024/03009831.76.4.253.

31. Isidori AM, Strollo F, Morè M, Caprio M, Aversa A, Moretti $\mathrm{C}$, et al. Leptin and Aging: Correlation with Endocrine Changes in Male and Female Healthy Adult Populations of Different Body Weights. J Clin Endocrinol Metab 2000, 85: 1954-1962. https://doi.org/10.1210/jcem.85.5.6572.

32. Harvey JA, Chastin SFM, Skelton DA. Prevalence of sedentary behavior in older adults: A systematic review. Int J Environ Res Public Health 2013,2;10(2): 6645-6661. https://doi.org/10.3390/ijerph10126645.

33. André $P$, Proctor $G$, Driollet B, Garcia-Esquinas E, LopezGarcia E, Gomez-Cabrero D, et al. The role of overweight in the association between the Mediterranean diet and the risk of type 2 diabetes mellitus: A mediation analysis among 21585 UK biobank participants. Int J Epidemiol. 2020, 49: 1582-1590. https://doi.org/10.1093/ije/dyaa103.

34. Bonaccio M, Bonanni AE, Castelnuovo A Di, De Lucia F, Donati MB, De Gaetano G, et al. Low income is associated with poor adherence to a Mediterranean diet and a higher prevalence of obesity: Cross-sectional results from the Moli-sani study. BMJ Open 2012, 2: 1685. https://doi.org/10.1136/bmjopen-2012-001685.

35. Cavaliere A, De Marchi E, Banterle A. Exploring the adherence to the mediterranean diet and its relationship with individual lifestyle: The role of healthy behaviors, pro-environmental behaviors, income, and education. Nutrients 2018, 10(2):141. https://doi.org/10.3390/nu10020141.

36. Kollmuss A, Agyeman J. Mind the Gap: Why do people act environmentally and what are the barriers to proenvironmental behavior? Environ Educ Res 2002, 8: 239-260.

https://doi.org/10.1080/13504620220145401.

37. Bonaccio M, Di Castelnuovo A, Costanzo S, De Lucia F, Olivieri $\mathrm{M}$, Donati $\mathrm{MB}$, et al. Nutrition knowledge is associated with higher adherence to Mediterranean diet and lower prevalence of obesity. Results from the Moli-sani study. Appetite 2013, 68: 139-146. https://doi.org/10.1016/j.appet.2013.04.026.

38. Ekman A, Dickman PW, Klint A, Weiderpass E, Litton JE. Feasibility of using web-based questionnaires in large population-based epidemiological studies. Eur J Epidemiol. 2006, 21: 103-111. https://doi.org/10.1007/s10654-005-6030-4 